\title{
Thermoresponsive and Redox Behaviors of Poly( $N$-isopropylacrylamide)-Based Block Copolymers Having TEMPO Groups as Their Side Chains
}

\author{
Toru Uemukai, Tomoya Hioki, and Manabu Ishifune \\ Department of Applied Chemistry, Faculty of Science and Engineering, Kinki University, 3-4-1 Kowakae, Higashi-Osaka, \\ Osaka 577-8502, Japan \\ Correspondence should be addressed to Manabu Ishifune; ishifune@apch.kindai.ac.jp
}

Received 18 April 2013; Revised 24 May 2013; Accepted 10 June 2013

Academic Editor: Haojun Liang

Copyright (C) 2013 Toru Uemukai et al. This is an open access article distributed under the Creative Commons Attribution License, which permits unrestricted use, distribution, and reproduction in any medium, provided the original work is properly cited.

\begin{abstract}
Thermoresponsive and redox-active block copolymers having 2,2,6,6-tetramethylpiperidine-1-oxyl (TEMPO) moieties have been synthesized by using the reversible addition-fragmentation chain transfer (RAFT) polymerization technique. $N$ Isopropylacrylamide (NIPAAm) and 2,2,6,6-tetramethylpiperidyl methacrylate (TEMPMA) monomers were copolymerized stepwise under RAFT polymerization conditions to afford the thermoresponsive block copolymers, PNIPAAm-block-PTEMPMA and PNIPAAm-block-PTEMPMA-block-PNIPAAm. Oxidation of tetramethylpiperidine groups in the copolymers successfully afforded the corresponding TEMPO-containing block copolymers. The resulting triblock copolymer was found to be thermoresponsive showing lower critical solution temperature (LCST) at $34^{\circ} \mathrm{C}$ in its aqueous solution. Redox behavior of the resulting copolymer was observed by cyclic voltammetry. The potential of anodic current peak changed below and above the LCST of the block copolymer. These results indicate that the phase transition of thermoresponsive polymer influences the redox potential of TEMPO moieties.
\end{abstract}

\section{Introduction}

Much attention has been paid to stimuli-responsive polymers in chemistry and materials science, because of their unique reversible change of physical properties in response to a chemical or physical stimulus [1-3]. Responsive behavior typically involves physical changes in polymer's properties. For instance, unique changes in solubility are often exhibited by the polymers that have lower critical solution temperature (LCST). While many synthetic polymers exhibit LCSTs, poly( $N$-isopropylacrylamide) (PNIPAAm) and its copolymers are the most popular materials with LCSTs. Drug delivery systems [4-6], chromatographic separations $[7,8]$, separation and purification of metal ions $[9,10]$, and molecular recognition [11] are among the most important fields in which thermoresponsive polymers are used. In previous study, we have found that the phase transition behavior of PNIPAAmbased polymer having pyrrolidine groups as side chains was influenced by $\mathrm{pH}$ values [12]. Their LCST's changes were influenced by deionization of pyrrolidine hydrogen chloride moieties. Moreover, the pyrrolidine side chains of the thermoresponsive copolymer promoted the aldol reaction between cyclohexanone and $p$-nitrobenzaldehyde in water, and the reaction proceeded most smoothly at its LCST. The thermoresponsive polymer in water aggregate to form a rather hydrophobic reaction field and the substrates are probably concentrated and promoted the aldol reaction in the resulting hydrophobic field. Thus, such a hydrophobic field formed by thermoresponsive polymers could be utilized for various organic reactions in aqueous media. Beside the $\mathrm{pH}$ dependence on phase transition, several examples of thermoresponsive polymers with redox responsiveness have been reported such as PNIPAAm-based polymers containing ferrocenyl pendant groups or 2,2,6,6-tetramethylpiperidine 1-oxyl (TEMPO) groups [13-16]. The polymers containing TEMPO moieties, which were prepared by the polymer reaction of $\operatorname{poly}(N$-acryloxysuccinimide) with a mixture of 4-amino TEMPO and isopropylamine, were reported to show redox-sensitive LCST behavior [14]. These polymers are promising for the application to the TEMPO-mediated 
redox reactions in the hydrophobic field generated by the phase transition of the thermoresponsive polymers. For this purpose it is important to control the repeat units sequence so that the redox centers are effectively surrounded by the thermoresponsive polymer chains. However, most hitherto known thermoresponsive polymers having TEMPO moieties have been prepared in a random manner [14-16], and few thermoresponsive behaviors with redox responsiveness of the corresponding polymers having block structures have been reported. In this study, sequence-ordered thermoresponsive polymers having TEMPO pendant groups as mediatory centers were synthesized by using the reversible additionfragmentation chain transfer (RAFT) polymerization technique, and thermoresponsivity and redox behaviors of the resulting polymers were investigated.

\section{Experimental}

2.1. General. IR spectra were obtained on an FT-IR-470 Plus spectrometer. ${ }^{1} \mathrm{H}$ NMR spectra were measured on a Varian OXFORD NMR300 (300 MHz) or JEOL JNM-AL400 $(400 \mathrm{MHz})$ spectrometer, and the chemical shift values $(\delta)$ were expressed in ppm downfield from the internal TMS standard. The molecular weights of polymers were determined by using a gel permeation chromatography (GPC). The GPC analyses were carried out on a Hitachi L-6000 high-performance liquid chromatograph, L-3350 RI detector, and Shodex GPC KF-804L column. THF was used as the eluent with a flow rate of $1.0 \mathrm{~mL} / \mathrm{min}$, and molecular weight values were relative to the polystyrene standards (Shodex STANDARD SM-105 and SL-105). UV-visible spectra were recorded with Jasco V-630 spectrometer (Tokyo, Japan). ESR spectra were recorded by JEOL JES-PX1050. Cyclic voltammetry was measured by BAS CV-50.

2.2. Materials. 4-Cyano-4-[(dodecylsulfanylthiocarbonyl) sulfanyl]pentanoic acid was synthesized from $4,4^{\prime}$-azobis (4cyanopentanoic acid), carbon disulfide (Wako Pure Chemical Industries, Ltd., Osaka, Japan) and 1-dodecanethiol (SIGMAALDRICH) [17]. N-Isopropylacrylamide (NIPAAm) (Wako Pure Chemical Industries, Ltd., Osaka, Japan) was purified by recrystallization from hexane-benzene (95:5). 2,2 ${ }^{\prime}$-Azobisisobutyronitrile (AIBN) as a radical initiator was recrystallized from methanol below $40^{\circ} \mathrm{C}$. Tetrahydrofuran (THF) (Wako Pure Chemical Industries, Ltd., Osaka, Japan) was distilled from Na-benzophenoneketyl under Ar atmosphere. 2,2,6,6Tetramethyl-4-piperidyl methacrylate (TEMPMA) and the other materials were commercially available and used without further purification.

2.3. Synthesis of Poly(TEMPMA-ran-NIPAAm) (1). TEMPMA (0.26 g, $1.1 \mathrm{mmoL})$, NIPAAm (3.16 g, $27.9 \mathrm{mmoL})$, AIBN $(0.1 \mathrm{moL} \%$ relative to monomers) as an initiator, and 4-cyano-4-[(dodecylsulfanylthiocarbonyl)sulfanyl]pentanoic acid $(1.0 \mathrm{~mol} \%$ relative to monomers) were dissolved in THF $(4 \mathrm{~mL})$. After oxygen was removed repeatedly by freeze-evacuation-thaw cycles, polymerization was carried out at $60^{\circ} \mathrm{C}$ for $15 \mathrm{~h}$. After cooling in an ice-water bath, the polymer solution was poured into a large amount of diethyl ether, and the resulting precipitate was filtered and dried under reduced pressure at room temperature. The crude polymer was purified by reprecipitation from THF into diethyl ether. ${ }^{1} \mathrm{H}$ NMR $\left(\mathrm{CDCl}_{3}\right) \delta$ 0.88-2.87 (m, NIPAAm unit, TEMPAMA unit), 3.87-4.12 (bs, $\left.\mathrm{CH}\left(\mathrm{CH}_{3}\right)_{2}\right), 5.03-5.19$ (bs, O-CH); IR (KBr) 3299, 3077, 1726, 1653, $1545 \mathrm{~cm}^{-1}$.

\subsection{Synthesis of PNIPAAm-block-PTEMPMA-block- PNIPAAm}

2.4.1. RAFT Reagent Terminated PNIPAAm. NIPAAm (6.40 g, $56.6 \mathrm{mmoL})$, AIBN (0.1 moL\% relative to monomer) as an initiator, and 4-cyano-4-[(dodecylsulfanylthiocarbonyl)sulfanyl]pentanoic acid $(1.0 \mathrm{moL} \%$ relative to monomer) as a chain transfer reagent (RAFT reagent) were dissolved in THF $(6 \mathrm{~mL})$. After oxygen was removed repeatedly by freeze-evacuation-thaw cycles, polymerization was carried out at $60^{\circ} \mathrm{C}$ for $15 \mathrm{~h}$. After cooling in an ice-water bath, the polymer solution was poured into a large amount of diethyl ether, and the resulting precipitate was filtered and dried under reduced pressure at room temperature. The crude polymer was purified by reprecipitation from THF into diethyl ether. ${ }^{1} \mathrm{H}$ NMR $\left(\mathrm{CDCl}_{3}\right) \delta 1.02-3.17(\mathrm{~m}$, $\left.\mathrm{CH}_{2}-\mathrm{CH}, \mathrm{CH}\left(\mathrm{CH}_{3}\right)_{2}\right)$, 3.85-4.18 (bs, $\left.\mathrm{CH}\left(\mathrm{CH}_{3}\right)_{2}\right)$; IR (KBr) $3293,3079,1650,1550 \mathrm{~cm}^{-1}$.

2.4.2. PNIPAAm-block-PTEMPMA (2). TEMPMA (1.03 g, $4.55 \mathrm{mmoL})$, AIBN (0.1 moL\% relative to monomer) as an initiator, and RAFT reagent terminated PNIPAAm $(1.0 \mathrm{moL} \%$ relative to monomer) as a macrochain transfer agent (macroCTA) were dissolved in THF $(4 \mathrm{~mL})$. After oxygen was removed repeatedly by freeze-evacuation-thaw cycles, polymerization was carried out at $60^{\circ} \mathrm{C}$ for $60 \mathrm{~h}$. After cooling in an ice-water bath, the polymer solution was poured into a large amount of diethyl ether, and the resulting precipitate was filtered and dried under reduced pressure at room temperature. The crude polymer was purified by reprecipitation from THF into diethyl ether. ${ }^{1} \mathrm{H}$ NMR $\left(\mathrm{CDCl}_{3}\right) \delta 0.76-$ 2.85 (m, NIPAAm unit, TEMPAMA unit), 3.86-4.19 (bs, $\left.\mathrm{CH}\left(\mathrm{CH}_{3}\right)_{2}\right)$, 4.96-5.18 (bs, O-CH); IR (KBr) 3299, 3074, 1730, $1652,1559 \mathrm{~cm}^{-1}$.

2.4.3. PNIPAAm-block-PTEMPMA-block-PNIPAAm (3). NIPAAm (1.66 g, $1.47 \mathrm{mmoL})$, AIBN (1.7 mg, $0.01 \mathrm{mmoL})$ as an initiator and PNIPAAm-block-PTEMPMA (2) (0.69 g) as a macro-CTA were dissolved in THF $(4 \mathrm{~mL})$. After oxygen was removed repeatedly by freeze-evacuation-thaw cycles, polymerization was carried out at $60^{\circ} \mathrm{C}$ for $80 \mathrm{~h}$. After cooling in an ice-water bath, the polymer solution was poured into a large amount of diethyl ether, and the resulting precipitate was filtered and dried under reduced pressure at room temperature. The crude polymer was purified by reprecipitation from THF into diethyl ether. ${ }^{1} \mathrm{H}$ NMR $\left(\mathrm{CDCl}_{3}\right) \delta$ 0.80-3.17 (m, NIPAAm unit, TEMPAMA unit), 3.90-4.17 (bs, $\left.\mathrm{CH}\left(\mathrm{CH}_{3}\right)_{2}\right)$, 4.98-5.18 (bs, O-CH); IR ( $\mathrm{KBr}$ ) $3298,3074,1726,1649,1546 \mathrm{~cm}^{-1}$. 
2.5. Oxidation of Tetramethylpiperidine Moieties in the Polymers. Polymer having TEMPMA moieties $(\mathbf{1}, \mathbf{2}$, or $\mathbf{3})$ $(0.80 \mathrm{~g}), \mathrm{Na}_{2} \mathrm{WO}_{4} \cdot 2 \mathrm{H}_{2} \mathrm{O}(0.37 \mathrm{~g}, 1.1 \mathrm{mmoL})$, and $30 \% \mathrm{H}_{2} \mathrm{O}_{2}$ $(6 \mathrm{~mL})$ was dissolved in $\mathrm{H}_{2} \mathrm{O}(24 \mathrm{~mL})$. This reaction mixture was stirred at $4^{\circ} \mathrm{C}$ for $24 \mathrm{~h}$. Into the mixture was added $\mathrm{K}_{2} \mathrm{CO}_{3}$ until the solution was saturated. The aqueous solution was extracted with ethyl acetate until the organic layer was colorless. The combined organic layers were dried over $\mathrm{MgSO}_{4}$ and concentrated under reduced pressure to give an orange to pale red powder.

Poly(TEMPOMA-ran-NIPAAm); IR (KBr) 3308, 3081, $1719,1653,1539 \mathrm{~cm}^{-1}$.

PNIPAAm-block-PTEMPOMA; IR (KBr) 3298, 3080, $1726,1649,1546 \mathrm{~cm}^{-1}$.

PNIPAAm-block-PTEMPOMA-block-PNIPAAm; IR (KBr) 3297, 3080, 1730, 1650, $1548 \mathrm{~cm}^{-1}$.

2.6. Measurement of Cloud Points. The cloud points of aqueous polymer solutions $(1.0 \mathrm{w} / \mathrm{v} \%)$ were determined by transmittance measurements using a UV-visible spectrometer equipped with a temperature controller. The transmittance of the polymer solutions was recorded as a function of temperature $\left(15-45^{\circ} \mathrm{C}\right)$. The wavelength was fixed at $500 \mathrm{~nm}$, and the temperature was raised at $1.0^{\circ} \mathrm{C} / \mathrm{min}$. The cloud points of the polymer solutions were defined as the temperatures when the transmittance was decreased to half of final transmittance from initial.

2.7. Electrochemical Testing of the Copolymers. Cyclic voltammograms were measured in $0.1 \mathrm{M} \mathrm{KCl}$ aqueous solution after bubbling with nitrogen gas $(20 \mathrm{~min})$ at various temperatures $\left(5-55^{\circ} \mathrm{C}\right)$. As a working electrode and a counter electrode were used a GCE Glassy carbon (BAS $6.0 \times$ $1.6 \mathrm{~mm}$ ) and a platinum wire (BAS VC-3 cell $5 \mathrm{~cm} \mathrm{Pt}$ ), respectively, and a reference electrode consisted of $\mathrm{Ag} / \mathrm{AgCl}$ (BAS RE-1B). Scan rate was $100 \mathrm{mV} / \mathrm{s}$. The concentration of aqueous solution of poly(TEMPOMA-ran-NIPAAm) or PNIPAAm-block-PTEMPOMA was adjusted at $2.0 \mathrm{mM}$ (based on TEMPO moieties). The concentration of aqueous solution of PNIPAAm-block-PTEMPOMA-block-PNIPAAm was $0.47 \mathrm{~g} / \mathrm{mL}$.

\section{Results and Discussion}

3.1. Synthesis and Characterization of Poly(TEMPOMA-ranNIPAAm). Thermoresponsive polymers having 2,2,6,6tetramethylpiperidine-1-oxyl (TEMPO) pendant groups as mediatory centers were synthesized by using the reversible addition-fragmentation chain transfer (RAFT) polymerization technique and oxidation of 2,2,6,6-tetramethyl4-piperidyl methacrylate (TEMPMA) units. $\mathrm{N}$-Isopropylacrylamide (NIPAAm) and TEMPMA were copolymerized in a random manner in the presence of 4-cyano-4-[(dodecylsulfanylthiocarbonyl)sulfanyl]pentanoic acid to afford poly(TEMPMA-ran-NIPAAm) (Scheme 1). The resulting random copolymer was analyzed by ${ }^{1} \mathrm{H}$ NMR spectroscopy; the ratio of TEMPMA/NIPAAm units was determined to

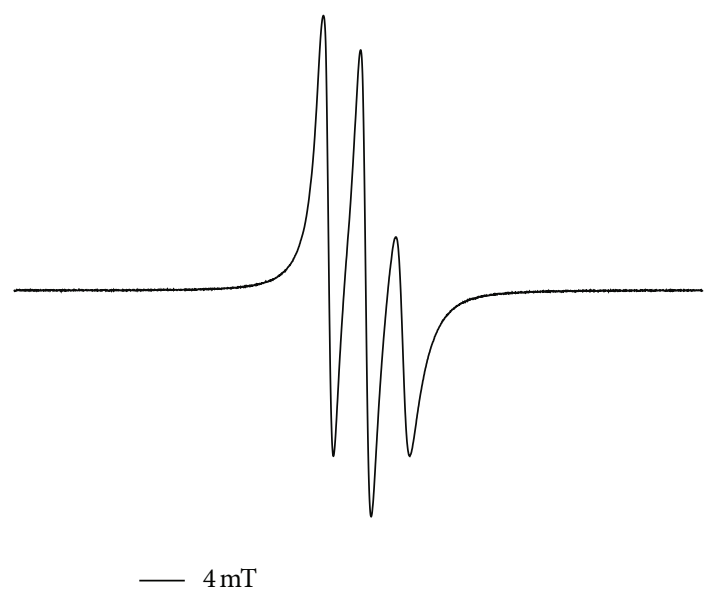

FIGURE 1: ESR spectrum of poly(TEMPOMA-ran-NIPAAm).

be $6: 94$. The number average molecular weight $\left(M_{n}\right)$ of the random copolymer was estimated by GPC based on polystyrene standard to be $4840\left(M_{w} / M_{n}=1.26\right)$. Oxidation of the TEMPMA units afforded poly(TEMPOMA-ranNIPAAm). The resulting TEMPO-containing random copolymer was characterized by ESR spectroscopy, and its spectrum showed characteristic three-line signals of a nitroxyl group (Figure 1) [14, 15]. The random copolymer, poly(TEMPMA-ran-NIPAAm), showed thermoresponsivity, and its lower critical solution temperature (LCST) was observed at $31^{\circ} \mathrm{C}$, which was slightly increased to $33^{\circ} \mathrm{C}$ after oxidation of tetramethylpiperidine moieties (Figure 2(a)). The transmittance of the oxidized random copolymer solution was observed to be decreased from $25^{\circ} \mathrm{C}$, and at $0.1^{\circ} \mathrm{C} / \mathrm{min}$ of heating rate the thermoresponsivity was still slow, but the LCST was observed at $32^{\circ} \mathrm{C}$, which was almost unchanged in comparison with that before oxidation of the TEMPMA moieties.

3.2. Synthesis and Characterization of the Diblock and Triblock Copolymers. The diblock and triblock polymers were also synthesized by using the RAFT polymerization technique and oxidation of TEMPMA units. Firstly, the RAFT reagent terminated PNIPAAm was prepared, and, in the second step, PNIPAAm-block-PTEMPMA was synthesized by using the RAFT reagent terminated PNIPAAm as a macro-chain transfer agent (macro-CTA) (yield 58\%). Finally, PNIPAAmblock-PTEMPMA-block-PNIPAAm was synthesized by using the resulting diblock polymer as a macro-CTA (yield 94\%) (Scheme 2). The $M_{n}$ of the resulting block polymers having TEMPO precursor as side chains were estimated by determining the molar ratio of the repeating units and the end group from the ratio of signal intensities of $-\mathrm{NHCH}\left(\mathrm{CH}_{3}\right)_{2}$ of NIPAAm units, the proton at 4-position of piperidine moieties, and $-\mathrm{S}-\mathrm{CH}_{2}-$ of the end group in the ${ }^{1} \mathrm{H}$ NMR spectra. The molecular weight increased stepwise with the progress of polymerization and the $M_{n}$ values estimated from ${ }^{1} \mathrm{H}$ NMR were almost same as those estimated from GPC (Table 1). Oxidation of tetramethylpiperidine moieties in the resulting diblock and triblock copolymers 
TABLE 1: Molecular weight data of the resulting copolymers.

\begin{tabular}{|c|c|c|c|c|}
\hline & Content of TEMPMA units ${ }^{\mathrm{a}}(\%)$ & $M_{n}^{\mathrm{a}}$ & $M_{n}^{\mathrm{b}}$ & $M_{w} / M_{n}{ }^{\mathrm{b}}$ \\
\hline Poly(TEMPOMA-ran-NIPAAm) 1 & 6 & - & 4840 & 1.26 \\
\hline RAFT reagent terminated PNIPAAm & - & 6310 & 6600 & 1.20 \\
\hline PNIPAAm-block-PTEMPMA 2 & 4 & 7750 & 6970 & 1.17 \\
\hline PNIPAAm-block-PTEMPMA-block-PNIPAAm 3 & 1 & 15200 & 13940 & 1.35 \\
\hline
\end{tabular}

${ }^{a}$ Determined by integrated intensity of ${ }^{1} \mathrm{H}$ NMR spectra. ${ }^{\mathrm{b}}$ Estimated by GPC based on polystyrene standard in THF.
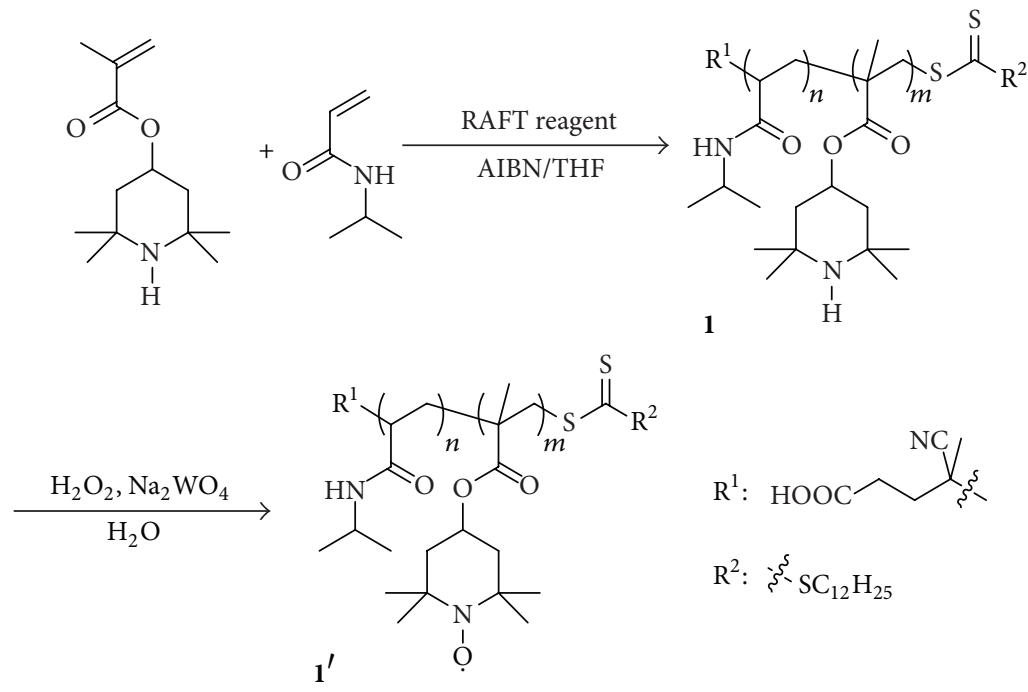

SCHEME 1: Synthesis of poly(TEMPOMA-ran-NIPAAm).

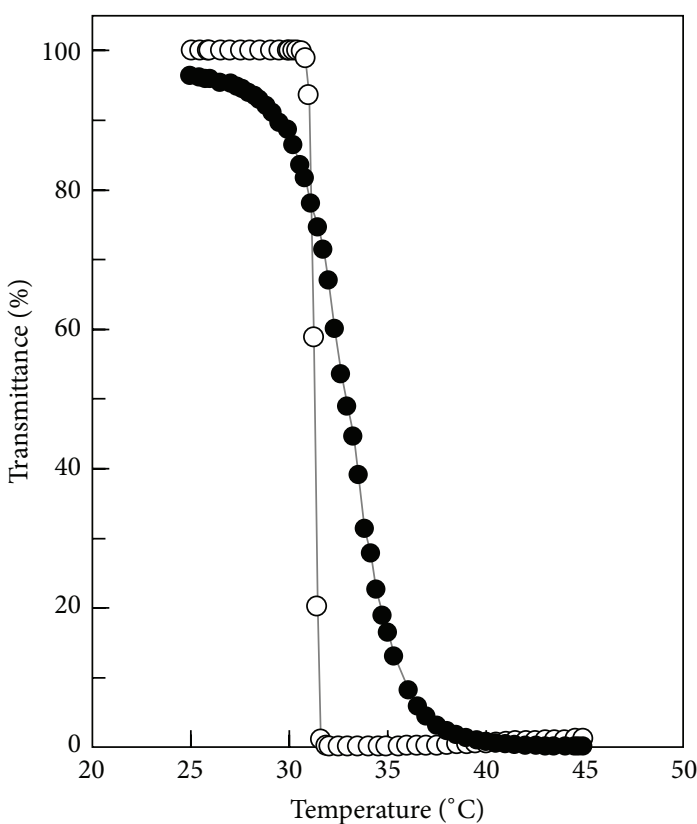

(a)

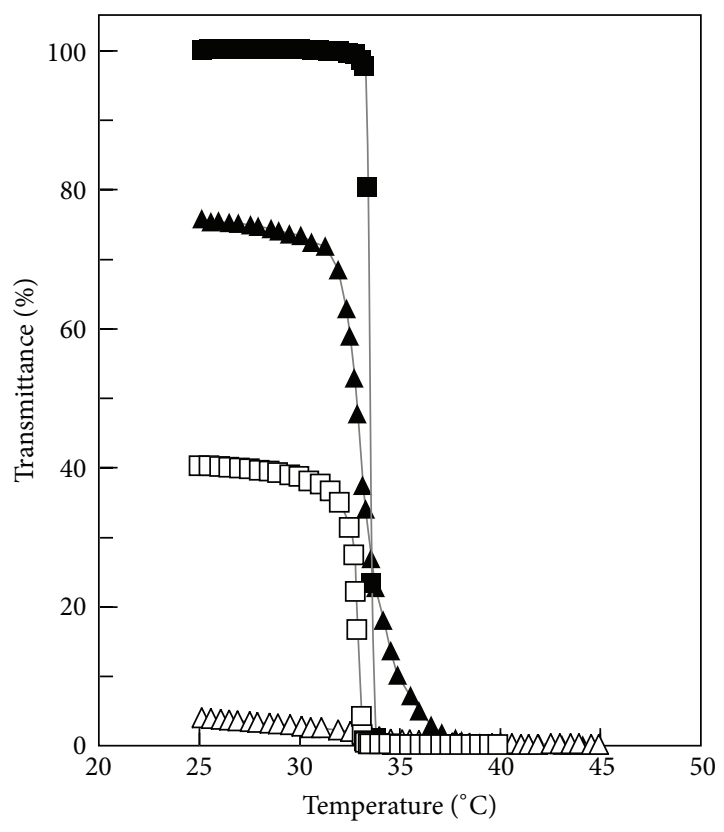

(b)

FIGURE 2: Temperature dependence of transmittance of $10 \mathrm{mg} / \mathrm{mL}$ aqueous solutions of (a) poly(TEMPMA-ran-NIPAAm) (1) (solid circle), poly(TEMPOMA-ran-NIPAAm) (1') (open circle); (b) PNIPAAm-block-PTEMPMA (2) (solid triangle) PNIPAAm-block-PTEMPOMA (2') (open triangle); PNIPAAm-block-PTEMPOMA-block-PNIPAAm (3) (solid square) and PNIPAAm-block-PTEMPOMA-block-PNIPAAm $\left(\mathbf{3}^{\prime}\right)$ (open square). 


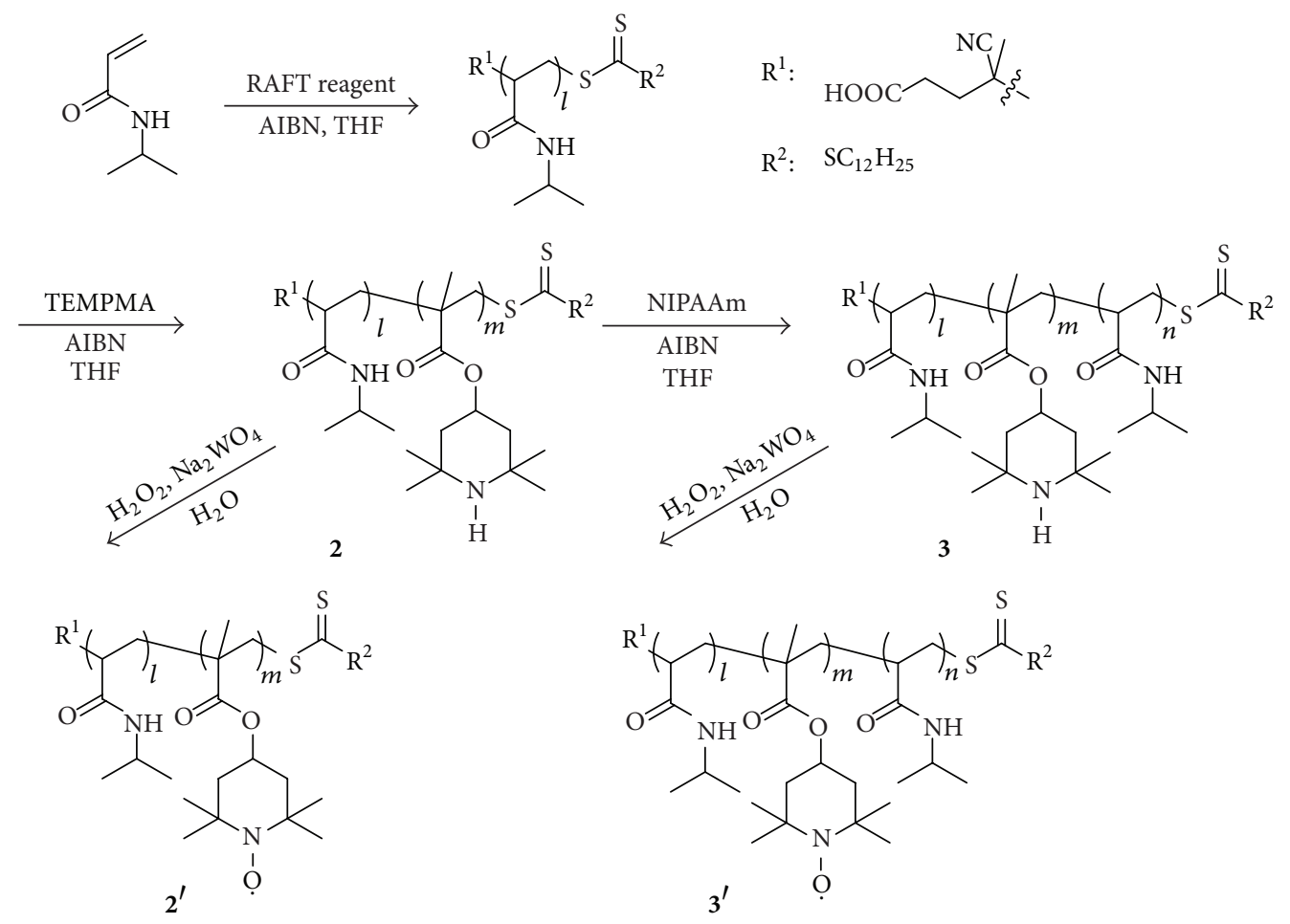

SCHEME 2: Synthesis of the block polymers consisting of NIPAAm and TEMPOMA units.

afforded PNIPAAm-block-PTEMPOMA and PNIPAAmblock-PTEMPOMA-block-PNIPAAm. The block polymers having TEMPO moieties as side chains were characterized by ESR spectroscopy, and their spectra showed characteristic three-line signals of nitroxyl groups. The diblock and triblock copolymers containing TEMPMA and NIPAAm groups showed thermoresponsivity, and their LCSTs were observed at $33^{\circ} \mathrm{C}$ and $34^{\circ} \mathrm{C}$, respectively. After oxidation of tetramethylpiperidine moieties, the diblock copolymer became insoluble in water; on the other hand, the triblock copolymer was found to have LCST at $33^{\circ} \mathrm{C}$ (Figure 2(b)). The molecular weight of water-insoluble diblock copolymer was 6970 and contained $4 \%$ of TEMPO moiety, while that of the corresponding random copolymers containing $6 \%$ of TEMPO moiety was 4840 and soluble in water. Thus a continuous structure of TEMPO moieties probably leads to the insolubility in water, and the NIPAAm unit sequence seems to be too short to form a polymer micelle. On the other hand, TEM images of the triblock copolymer aggregates obtained from their aqueous solutions showed $c a .50 \mathrm{~nm}$ of spheres under LCST, and these spherical particles aggregated to form more than $100 \mathrm{~nm}$ of clusters over LCST. Moreover, the initial transmittance of the oxidized triblock copolymer solution was observed to be $40 \%$ (Figure 2(b)). These results indicate the triblock copolymers form a polymer micelle.

3.3. Thermoresponsive Behavior of the Resulting Copolymers. TEMPO derivatives are reduced with $\mathrm{L}$-ascorbic acid to form the corresponding hydroxylamine [18]. The thermoresponsive behavior of the resulting random and block copolymers having TEMPO moieties was observed in $0.1 \mathrm{M}$ aqueous solution of $\mathrm{Na}_{2} \mathrm{SO}_{4}$ in presence of $\mathrm{L}$-ascorbic acid. The solution of the random copolymer was found to show LCST at $22^{\circ} \mathrm{C}$ in $0.1 \mathrm{M} \mathrm{Na}_{2} \mathrm{SO}_{4}$, and the LCST value increased to $33^{\circ} \mathrm{C}$ with increasing concentration of L-ascorbic acid because of the reduction of the TEMPO moieties (Figure 3(a)). The similar PNIPAAm-based polymer having TEMPO moieties has been reported to show almost the same LCST changes from $19^{\circ} \mathrm{C}$ to $33^{\circ} \mathrm{C}$ under reduction conditions with L-ascorbic acid [14]. On the other hand, the diblock polymer was slightly soluble in $0.1 \mathrm{M} \mathrm{Na}_{2} \mathrm{SO}_{4}$, and after $6.4 \mathrm{mM}$ ascorbic acid was added in $0.1 \mathrm{M} \mathrm{Na}_{2} \mathrm{SO}_{4}$ the diblock polymer became water-soluble and showed LCST at $30^{\circ} \mathrm{C}$ (Figure 4(a)). The LCST of the diblock polymer slightly decreased to $28^{\circ} \mathrm{C}$ with increasing concentration of L-ascorbic acid. The solution of the triblock copolymer was found to show LCST at $27.2^{\circ} \mathrm{C}$ in $0.1 \mathrm{M} \mathrm{Na}_{2} \mathrm{SO}_{4}$, and the LCST was almost unchanged $\left(28^{\circ} \mathrm{C}\right)$ with increasing concentration of L-ascorbic acid (Figure 5(a)). Reoxidation of the hydroxylamine-containing copolymer by $\mathrm{K}_{3}\left[\mathrm{Fe}(\mathrm{CN})_{6}\right]$ reverses the change of the LCST seen on reduction. The LCST of the reduced random copolymer was decreased with increasing concentration of $\mathrm{K}_{3}\left[\mathrm{Fe}(\mathrm{CN})_{6}\right]$ (Figure 3(b)). The reduced diblock copolymer became insoluble again when $4.8 \mathrm{mM} \mathrm{K}_{3}\left[\mathrm{Fe}(\mathrm{CN})_{6}\right]$ was added (Figure $4(\mathrm{~b})$ ), and the LCST of the reduced triblock copolymer was slightly decreased by adding $\mathrm{K}_{3}\left[\mathrm{Fe}(\mathrm{CN})_{6}\right]$ (Figure 5(b)). In Figures 4(b) and 5(b), initial transmittances of solutions of the random and triblock copolymers were decreased with increasing $\mathrm{K}_{3}\left[\mathrm{Fe}(\mathrm{CN})_{6}\right]$. It is due to the byproduct in the reaction of $\mathrm{K}_{3}\left[\mathrm{Fe}(\mathrm{CN})_{6}\right]$ with hydroxylamine. In both the reduction with L-ascorbic acid and the reoxidation with $\mathrm{K}_{3}\left[\mathrm{Fe}(\mathrm{CN})_{6}\right]$, the LCST's shifts 


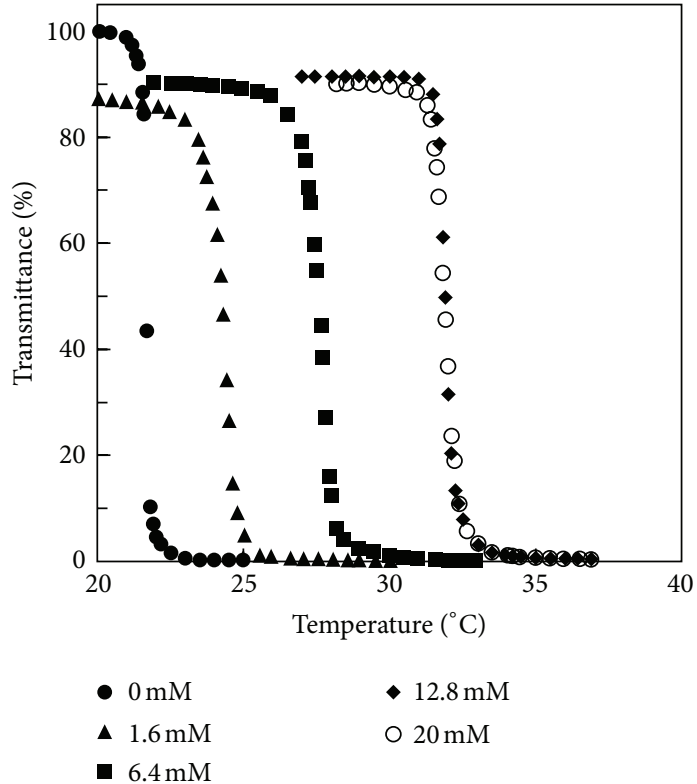

(a)

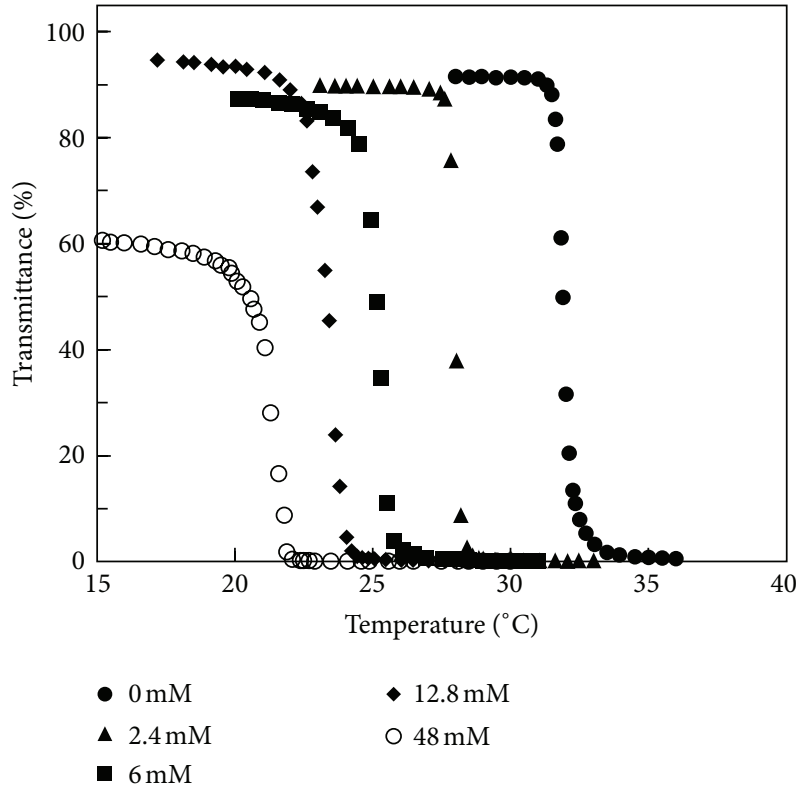

(b)

FIgURE 3: (a) Transmittance change of $10 \mathrm{mg} / \mathrm{mL}$ solutions of the poly(TEMPOMA-ran-NIPAAm) $\left(\mathbf{1}^{\prime}\right)$ in $0.1 \mathrm{M} \mathrm{Na}_{2} \mathrm{SO}_{4}$ aq in the presence of various amounts of L-ascorbic acid $0-20.0 \mathrm{mM}$ and (b) transmittance change of the resulting solutions of the corresponding reduced copolymer in the presence of various amounts of $\mathrm{K}_{3}\left[\mathrm{Fe}(\mathrm{CN})_{6}\right]$.

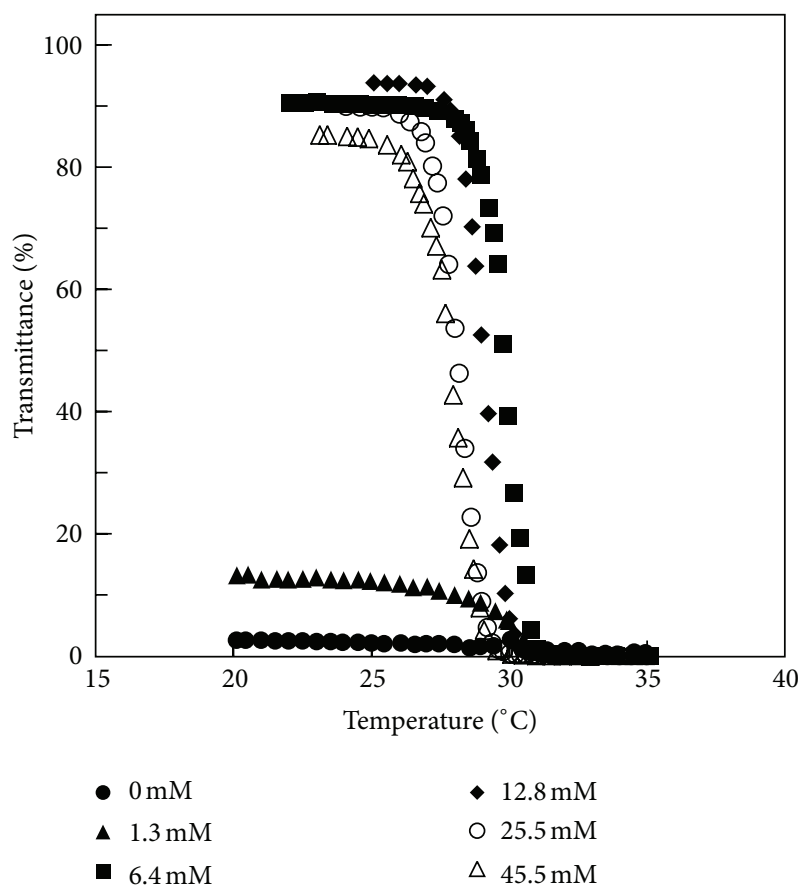

(a)

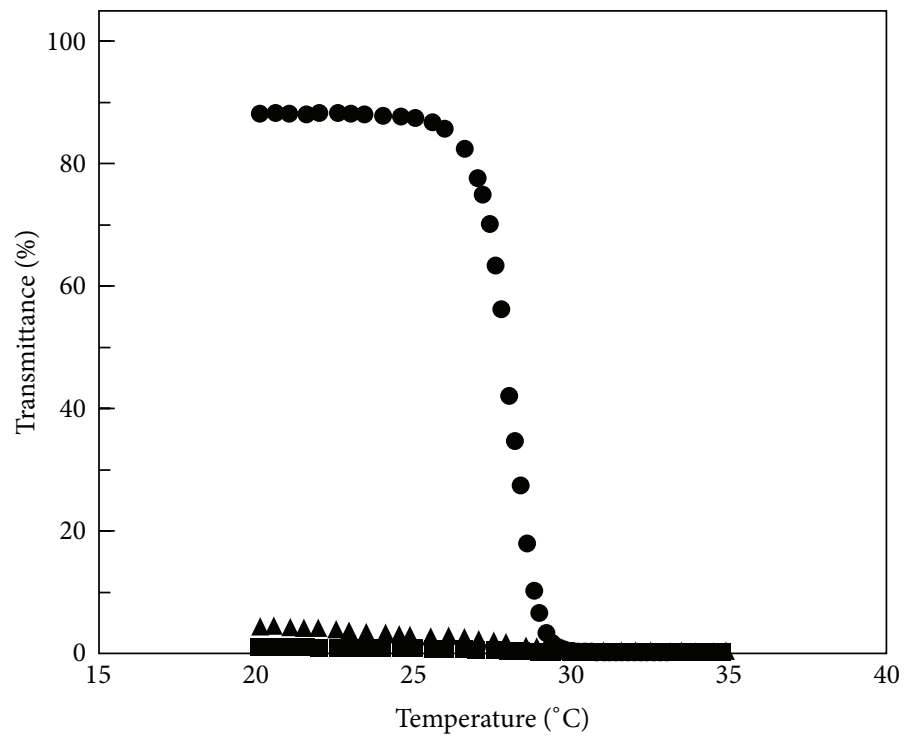

- $0 \mathrm{mM}$

- $4.8 \mathrm{mM}$

- $24 \mathrm{mM}$

(b)

Figure 4: (a) Transmittance change of $10 \mathrm{mg} / \mathrm{mL}$ solutions of the PNIPAAm-block-PTEMPOMA ( $\mathbf{2}^{\prime}$ ) in $0.1 \mathrm{M} \mathrm{Na}_{2} \mathrm{SO}_{4} a q$ in the presence of various amounts of L-ascorbic acid $0-45.5 \mathrm{mM}$ and (b) transmittance change of the resulting solutions of the corresponding reduced copolymer in the presence of various amounts of $\mathrm{K}_{3}\left[\mathrm{Fe}(\mathrm{CN})_{6}\right]$. 


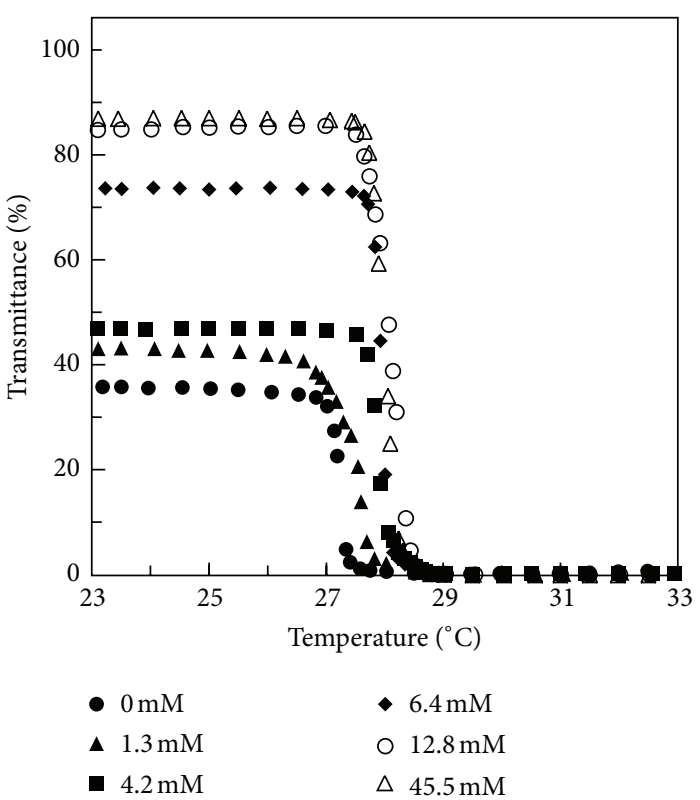

(a)

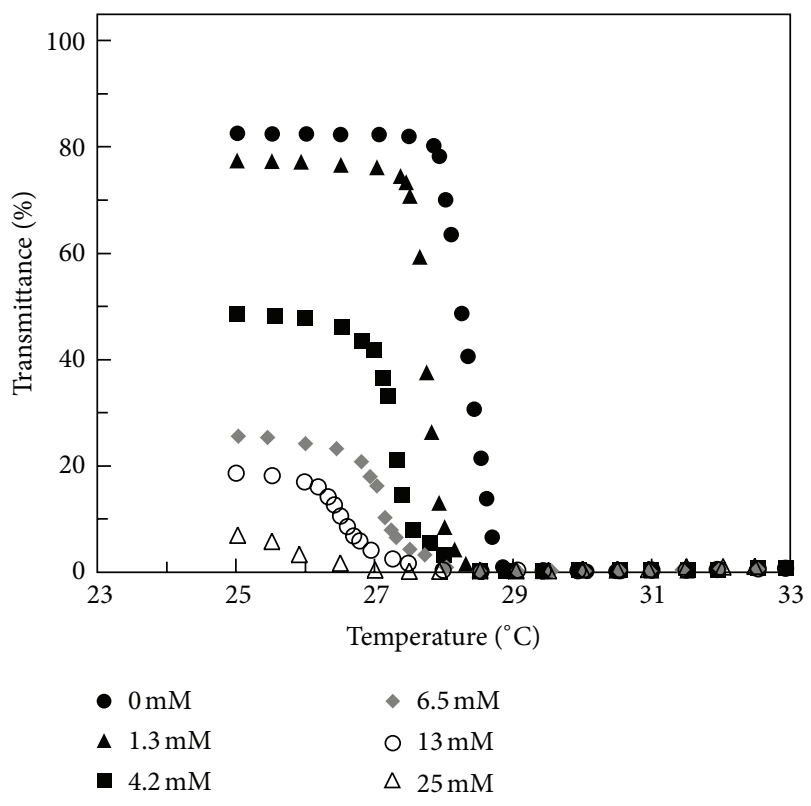

(b)

FIgure 5: (a) Transmittance change of $10 \mathrm{mg} / \mathrm{mL}$ solutions of the PNIPAAm-block-PTEMPOMA-block-PNIPAAm $\left(3^{\prime}\right)$ in $0.1 \mathrm{M} \mathrm{Na}_{2} \mathrm{SO}_{4}$ aq in the presence of various amounts of L-ascorbic acid 0-45.5 $\mathrm{mM}$ and (b) transmittance change of the resulting solutions of the corresponding reduced copolymer in the presence of various amounts of $\mathrm{K}_{3}\left[\mathrm{Fe}(\mathrm{CN})_{6}\right]$.

of the diblock and triblock copolymers were less than $2^{\circ} \mathrm{C}$. The LCST of PNIPAAm decreases $c a .2^{\circ} \mathrm{C}$ by the addition of ascorbic acid or $\mathrm{K}_{3}\left[\mathrm{Fe}(\mathrm{CN})_{6}\right]$ [14]; therefore, the phase transition behavior of the block copolymers seems to be not affected by the redox reactions of the TEMPO moieties. Thus, the TEMPO-containing units sequence and PNIPAAm chains individually function, and thermoresponsivity of the PNIPAAm chains predominantly appears in the block copolymers [19].

\subsection{Redox Behavior of the Resulting Copolymers at Various} Temperatures. The resulting copolymers having TEMPO groups were analyzed by cyclic voltammetry in $0.1 \mathrm{M}$ $\mathrm{KCl}$ aqueous solution at various temperatures $\left(5-55^{\circ} \mathrm{C}\right)$. In the cyclic voltammogram of the random copolymer, poly(TEMPOMA-ran-NIPAAm), a pair of anodic and cathodic peaks was observed at around $0.66 \mathrm{~V}$ under its LCST $\left(31^{\circ} \mathrm{C}\right.$ ) (Figure 6(a)), but no clear redox waves were observed over its LCST (Figure 6(b)). It was reported that TEMPO and the PNIPAAm having TEMPO groups have a redox potential of 0.63 and $0.66 \mathrm{~V}$ versus $\mathrm{Ag} / \mathrm{AgCl}$, respectively $[14,20]$. The diblock copolymer, PNIPAAmblock-PTEMPOMA, showed no redox waves, due to low solubility in water. On the other hand, triblock copolymer, PNIPAAm-block-PTEMPOMA-block-PNIPAAm, showed a redox wave at $0.72-0.73 \mathrm{~V}$ at lower than its LCST $\left(33^{\circ} \mathrm{C}\right)$ (Figure 7(a)). Moreover, the redox behavior of the TEMPO moieties in the triblock copolymer was found to be influenced by the phase transition of the PNIPAAm chains; namely, the anodic peaks were positively shifted to $0.81 \mathrm{~V}$ (Figure 7(b)). Below $33^{\circ} \mathrm{C}$, the PNIPAAm chains are hydrated and TEMPO moieties are located in hydrophilic environment. On the other hand, the environment around TEMPO moieties becomes relatively hydrophobic during the phase transition of the PNIPAAm chains above LCST. The positive shift of the anodic peak is probably due to the change of hydrophilicity in the polymer field. Thus, the phase transition of the triblock copolymer having thermoresponsive repeat units was found to influence the redox potential of TEMPO moieties.

\section{Conclusion}

PNIPAAm-based thermoresponsive random and block copolymers having TEMPO moieties as mediatory centers were successfully synthesized by using the RAFT polymerization technique. Both the random copolymer and the triblock copolymer having TEMPO moieties were found to have LCST at $33^{\circ} \mathrm{C}$, but the diblock copolymer was not soluble in water probably due to relatively hydrophobic sequence of TEMPO-containing unit at one side of the polymer chain. All copolymers containing TEMPO moieties exhibited redox sensitive LCST behavior. The observed LCSTs of the random copolymer in aqueous $\mathrm{Na}_{2} \mathrm{SO}_{4}$ increased from $22^{\circ} \mathrm{C}$ to $32^{\circ} \mathrm{C}$ by reduction with ascorbic acid and decreased in reverse by oxidation with $\mathrm{K}_{3}\left[\mathrm{Fe}(\mathrm{CN})_{6}\right]$. On the other hand, the LCST of the triblock copolymer was not so shifted under reduction and oxidation conditions. It is probably due to its block structure consisting of two relatively long PNIPAAm chains connected to the both sides of TEMPO-containing unit sequence. The TEM images of the triblock copolymer aggregates obtained from their aqueous solutions indicate the formation of a polymer micelle. Therefore the oxidation state 


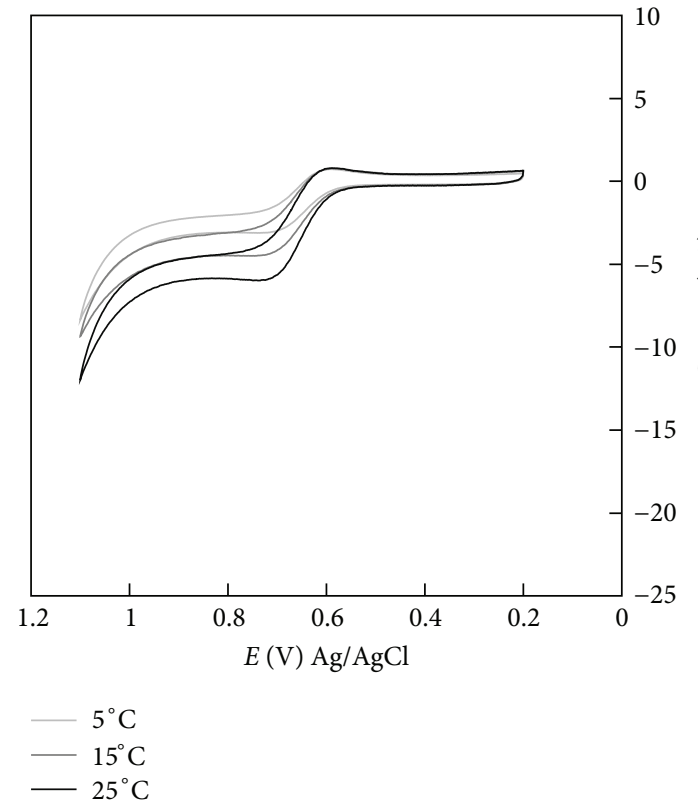

(a)

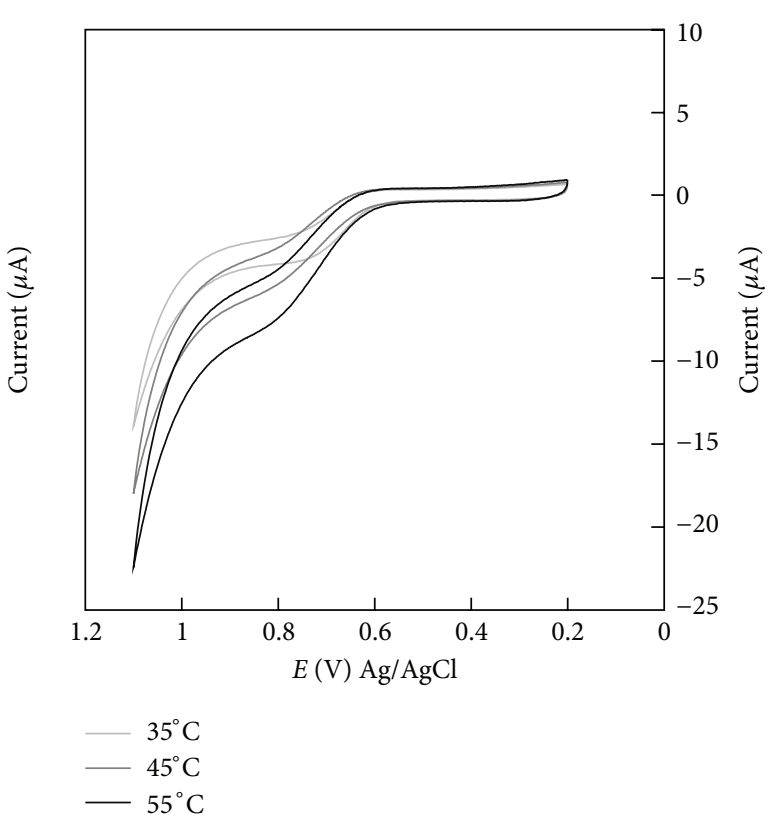

(b)

Figure 6: Cyclic voltammograms of poly(TEMPOMA-ran-NIPAAm) (1' $)$ in $0.1 \mathrm{M} \mathrm{KCl}$ aqueous solution at (a) 5,15 , and $25^{\circ} \mathrm{C}$, (b) 35,45 , and $55^{\circ} \mathrm{C}$.

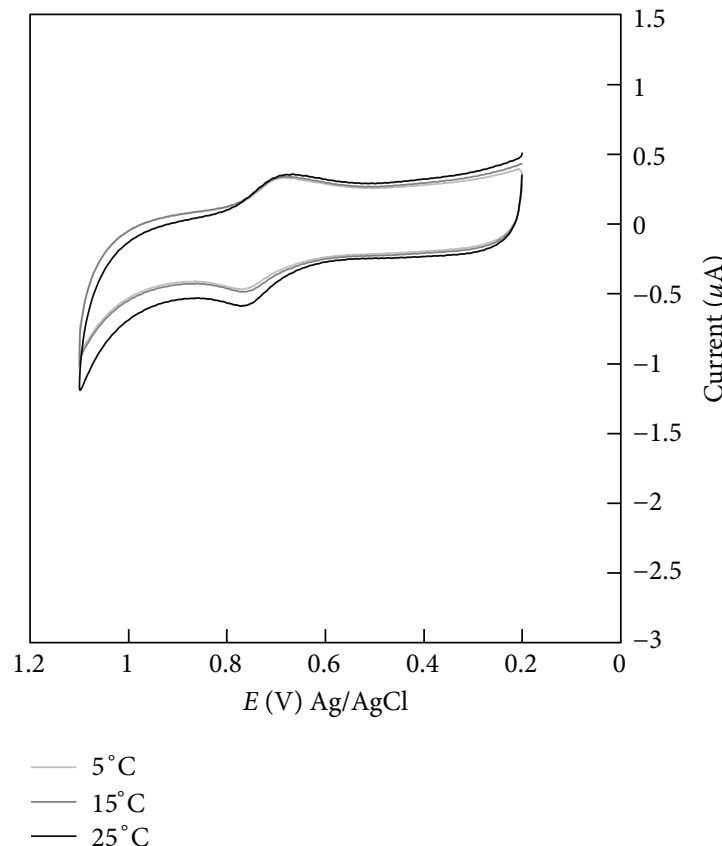

(a)

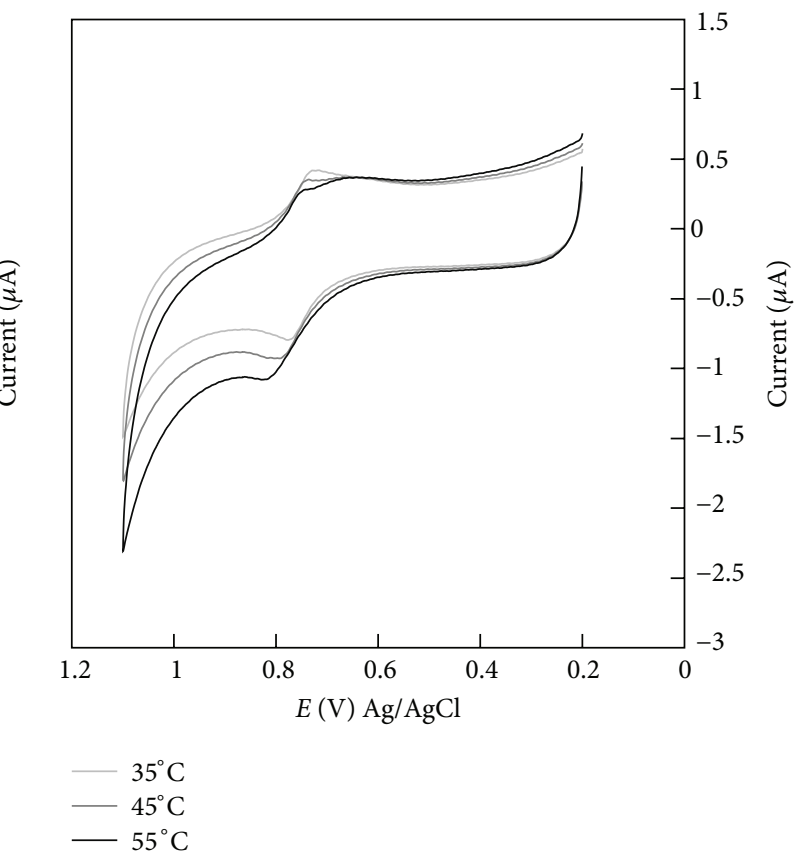

(b)

FIGURE 7: Cyclic voltammograms of PNIPAAm-block-PTEMPOMA-block-PNIPAAm $\left(\mathbf{3}^{\prime}\right)$ in $0.1 \mathrm{M} \mathrm{KCl}$ aqueous solution at (a) 5, 15, and $25^{\circ} \mathrm{C}$, (b) 35,45 , and $55^{\circ} \mathrm{C}$.

of the TEMPO moieties within the hydrophobic core of the micelle does not influence apparent solubility of the triblock copolymer, but the observed LCST is determined only by the thermoresponsivity of the PNIPAAm chains. The redox behavior of the TEMPO moieties in the triblock copolymer was found to be influenced by the phase transition of the
PNIPAAm chains. The anodic peaks of the TEMPO moieties were positively shifted above the LCST of the copolymers. This potential shift indicates that the TEMPO moieties are surrounded by the PNIPAAm chains and placed on relatively hydrophobic environment during the phase transition at LCST. We have also observed the concentration behavior 
of organic substrates into the hydrophobic field generated by PNIPAAm during the phase transition $[12,21]$. These phenomena encourage us to perform the TEMPO-mediated oxidation of organic compounds in the thermoresponsive polymer field. Further study on the utilization of the thermoresponsive block copolymers containing TEMPO moieties to organic reactions and also electrochemical reactions in aqueous media is currently in progress [22].

\section{References}

[1] H. G. Börner, H. Kühnle, and J. Hentschel, "Making "smart polymers" smarter: modern concepts to regulate functions in polymer science," Journal of Polymer Science Part A, vol. 48, no. 1, pp. 1-14, 2010.

[2] I. Tokarev, M. Motornov, and S. Minko, "Molecular-engineered stimuli-responsive thin polymer film: a platform for the development of integrated multifunctional intelligent materials," Journal of Materials Chemistry, vol. 19, no. 38, pp. 6932-6948, 2009.

[3] M. W. Urban, "Stratification, stimuli-responsiveness, self-healing, and signaling in polymer networks," Progress in Polymer Science, vol. 34, no. 8, pp. 679-687, 2009.

[4] N. Rapoport, "Physical stimuli-responsive polymeric micelles for anti-cancer drug delivery," Progress in Polymer Science, vol. 32, no. 8-9, pp. 962-990, 2007.

[5] M. Miyajima, M. Yoshida, H. Sato, H. Omichi, R. Katakai, and W. I. Higuchi, "In vitro release of 9- $\beta$-d-arabinofuranosyladenine from thermo-responsive copoly(acryloyl-1-proline methyl ester/styrene) gels," European Polymer Journal, vol. 30, no. 7, pp. 827-831, 1994.

[6] A. Matsumoto, T. Kurata, D. Shiino, and K. Kataoka, "Swelling and shrinking kinetics of totally synthetic, glucose-responsive polymer gel bearing phenylborate derivative as a glucosesensing moiety," Macromolecules, vol. 37, no. 4, pp. 1502-1510, 2004.

[7] T. Yakushiji, K. Sakai, A. Kikuchi, T. Aoyagi, Y. Sakurai, and T. Okano, "Effects of cross-linked structure on temperature-responsive hydrophobic interaction of poly $(\mathrm{N}$-isopropylacrylamide) hydrogel-modified surfaces with steroids," Analytical Chemistry, vol. 71, no. 6, pp. 1125-1130, 1999.

[8] H. Feil, Y. H. Bae, J. Feijen, and S. W. Kim, "Molecular separation by thermosensitive hydrogel membranes," Journal of Membrane Science, vol. 64, no. 3, pp. 283-294, 1991.

[9] X.-J. Ju, S.-B. Zhang, M.-Y. Zhou, R. Xie, L. Yang, and L.-Y. $\mathrm{Chu}$, "Novel heavy-metal adsorption material: ion-recognition P(NIPAM-co-BCAm) hydrogels for removal of lead(II) ions," Journal of Hazardous Materials, vol. 167, no. 1-3, pp. 114-118, 2009.

[10] M. J. Snowden, D. Thomas, and B. Vincent, "Use of colloidal microgels for the absorption of heavy metal and other ions from aqueous solution," The Analyst, vol. 118, no. 11, pp. 1367-1369, 1993.

[11] S. Gingter, E. Bezdushna, and H. Ritter, "Chiral recognition of macromolecules with cyclodextrins: $\mathrm{pH}$ - and thermosensitive copolymers from $N$-isopropylacrylamide and $N$-acryloyl-D/Lphenylalanine and their inclusion complexes with cyclodextrins," Beilstein Journal of Organic Chemistry, vol. 7, pp. 204-209, 2011.

[12] T. Uemukai and M. Ishifune, "Synthesis and catalytic activity of the thermoresponsive polymers having pyrrolidine side chains as base functionalities," Journal of Applied Polymer Science, vol. 129, no. 5, pp. 2554-2560, 2013.

[13] N. Kuramoto and Y. Shishido, "Property of thermo-sensitive and redox-active poly $(\mathrm{N}$-cyclopropylacrylamide-co-vinylferrocene) and poly( $N$-isopropylacrylamide-co-vinylferrocene)," Polymer, vol. 39, no. 3, pp. 669-673, 1998.

[14] H. Fu, D. M. Policarpio, J. D. Batteas, and D. E. Bergbreiter, "Redox-controlled 'smart' polyacrylamide solubility," Polymer Chemistry, vol. 1, no. 5, pp. 631-633, 2010.

[15] R. Yu, H. Zhao, Z. Zhao et al., "A pH dependent thermosensitive copolymer drug carrier incorporating 4-amino2,2,6,6-tetramethylpiperidin-1-oxyl (4- $\mathrm{NH}_{2}$-TEMPO) residues for electron spin resonance (ESR) labeling," Journal of Colloid and Interface Science, vol. 362, no. 2, pp. 584-593, 2011.

[16] P. Schattling, F. D. Jochum, and P. Theato, "Multi-responsive copolymers: using thermo, light- and redox stimuli as three independent inputs towards polymeric information processing," Chemical Communications, vol. 47, no. 31, pp. 8859-8861, 2011.

[17] G. Moad, Y. K. Chong, A. Postma, E. Rizzardo, and S. H. Thang, "Advances in RAFT polymerization: the synthesis of polymers with defined end-groups," Polymer, vol. 46, no. 19, pp. 8458 8468, 2005.

[18] H. Yang, J.-Q. Chen, J. Li, Y. Lv, and S. Gao, "The effect of TEMPO in the hydroxylation of benzene to phenol on the $\left[\left(\mathrm{CH}_{3}\right)_{4} \mathrm{~N}\right]_{4} \mathrm{PMo}_{11} \mathrm{VO}_{40} /$ ascorbic acid/TEMPO/O 2 catalytic system: formation of ascorbic acid radicals through hydrogen exchange of ascorbic acid and TEMPO," Applied Catalysis A, vol. 415-416, pp. 22-28, 2012.

[19] K. Skrabania, W. Li, and A. Laschewsky, "Synthesis of doublehydrophilic BAB triblock copolymers via RAFT polymerisation and their thermoresponsive self-assembly in water," Macromolecular Chemistry and Physics, vol. 209, no. 13, pp. 1389-1403, 2008.

[20] H. Nishide, S. Iwasa, Y.-J. Pu, T. Suga, K. Nakahara, and M. Satoh, "Organic radical battery: nitroxide polymers as a cathode-active material," Electrochimica Acta, vol. 50, no. 2-3, pp. 827-831, 2004.

[21] M. Ishifune, R. Suzuki, M. Yamane, H. Tanabe, Y. Nakagawa, and K. Uchida, "Polymerization of acrylamide in aqueous solution of poly $(N$-isopropylacrylamide) at lower critical solution temperature," Journal of Macromolecular Science Part A, vol. 45, no. 7, pp. 523-528, 2008.

[22] T. Uemukai, T. Hioki, and M. Ishifune, "Preparation of thermoresponsive polymer-modified electrodes having a TEMPO moiety," Electrochemistry, vol. 81, no. 5, pp. 383-387, 2013. 

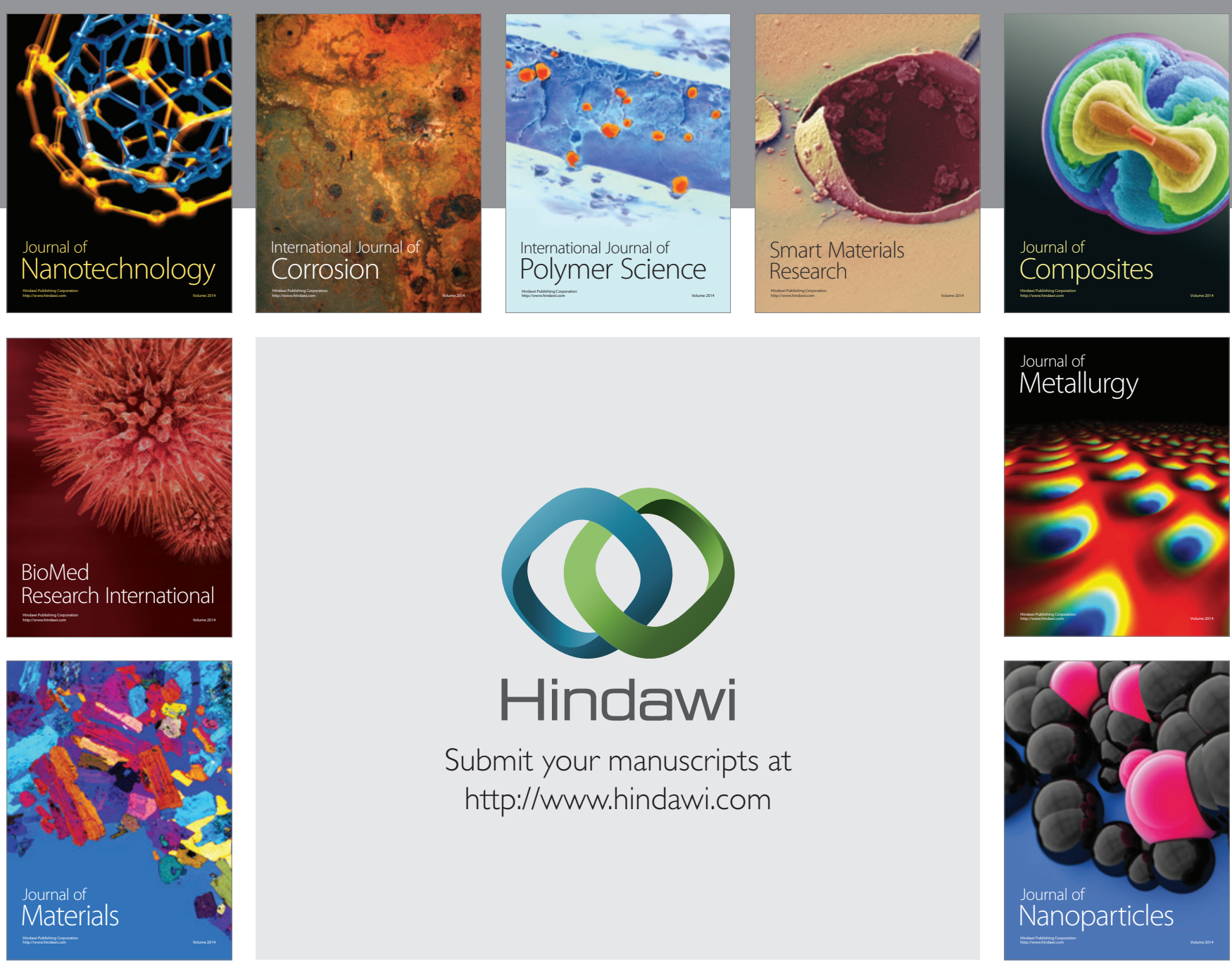

Submit your manuscripts at http://www.hindawi.com
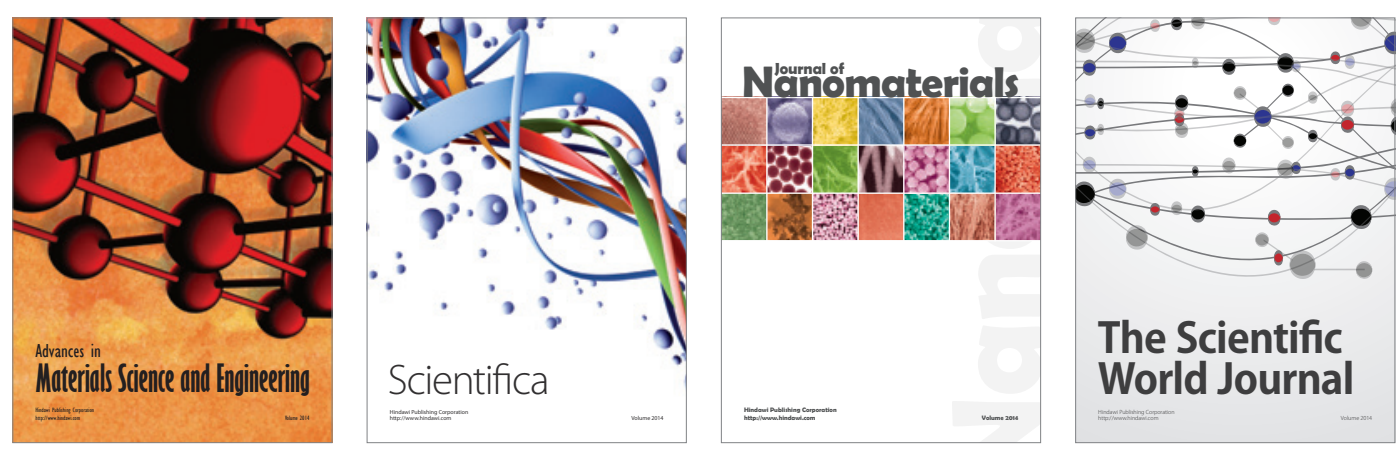

\section{The Scientific World Journal}
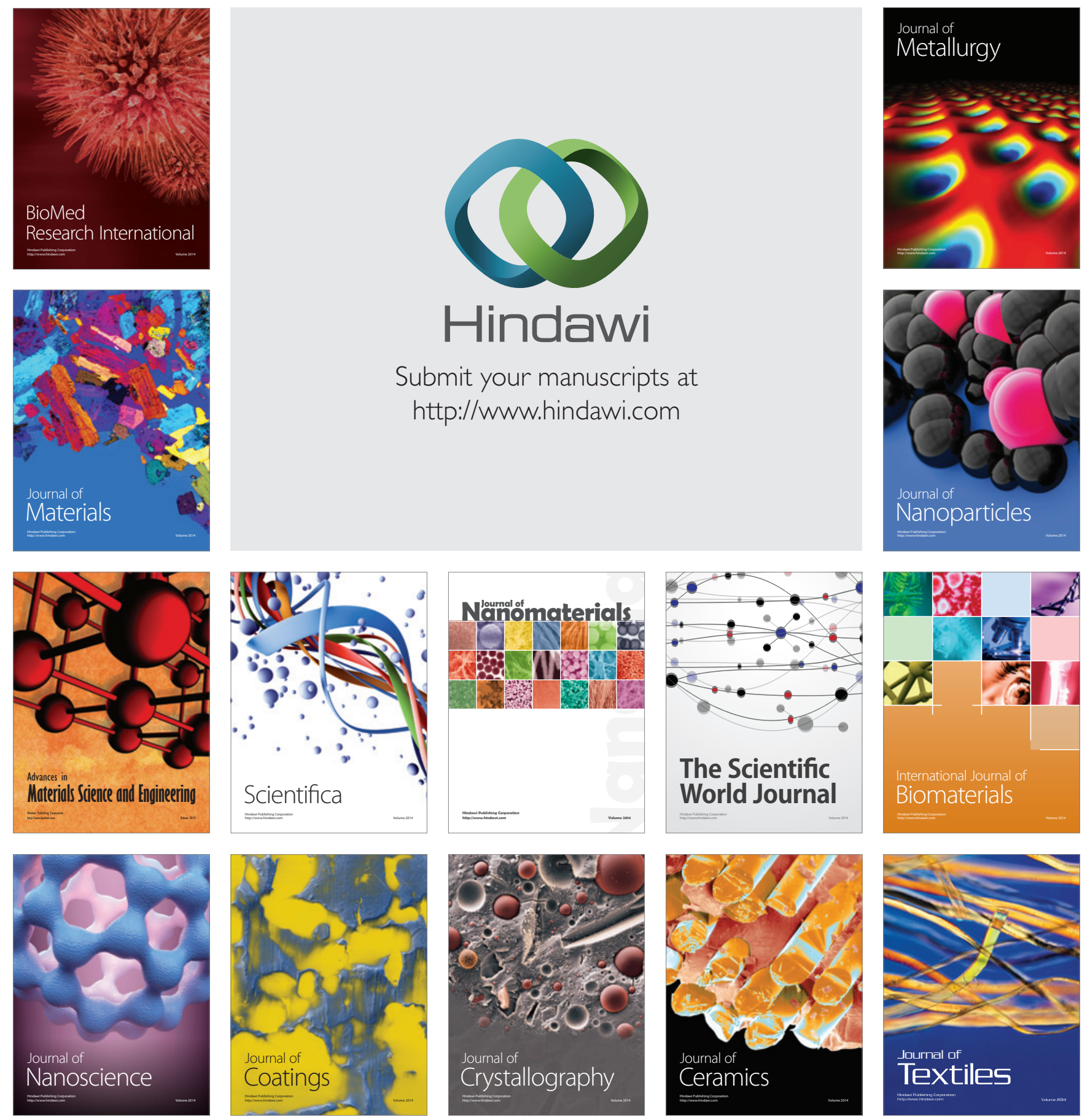